\title{
Impact of the Benefit Function Slope on the Advantage of Spatially Discriminating the Pollution Abatement Effort
}

\author{
François Destandau ${ }^{1}$ \\ ${ }^{1}$ Laboratory of Territorial Water and Environment Management (GESTE) UMR ENGEES-IRSTEA, Strasbourg \\ Cedex, France \\ Correspondence: François Destandau, Laboratory of Territorial Water and Environment Management (GESTE) \\ UMR ENGEES-IRSTEA, Associate researcher at BETA, UMR 7522 CNRS, Strasbourg Cedex, France. Tel: \\ 33-38-824-8240. E-mail: francois.destandau@engees.unistra.fr
}

\author{
Received: July 19, 2013 Accepted: September 2, 2013 Online Published: September 23, 2013 \\ doi:10.5539/ep.v2n4p101 URL: http://dx.doi.org/10.5539/ep.v2n4p101
}

\begin{abstract}
Many articles have dealt with the advantages of spatially discriminating the abatement effort when the pollution is non-uniformly mixed. However, few authors have attempted to identify the impact of certain model parameters on the advantage of this discrimination. These parameters are the transfer coefficients, the parameters of the abatement cost function or the level of the quality standard. In this article, we studied the role of the slope of the environmental benefit function on the advantages of spatially discriminating pollution abatement efforts. It appears that the relative increase in the net social benefit between a uniform and a perfectly discriminated control is not affected by this slope. However, in the case of partial discrimination, a steeper benefit slope increases the optimal number of zones.
\end{abstract}

Keywords: pollution control, discrimination of abatement effort, discrimination advantage, environmental benefit function

\section{Introduction}

The American Clean Air Act of 1970 and, more precisely, the introduction of tradable permits to reduce air pollution in the USA, has encouraged economists to take a closer look at the spatial discrimination of pollution control instruments: prices differentiated according to the buyer and the seller or different exchange markets for tradable permits, and different tax rates depending on location for emission taxes. In theory, a uniform instrument makes it possible to minimize the cost of total emission reduction by equalizing the marginal abatement costs, but not to reduce the ambient quality at minimal cost if the impact of emissions is spatially heterogeneous (Montgomery, 1972; Tietenberg, 1974).

Two types of optimization programs were developed to demonstrate the effectiveness of a spatially discriminated policy (different marginal costs, or abatement efforts, depending on the location of the emitters). The first type aimed at reaching quality standards at a minimum cost (Atkinson \& Lewis, 1974; Destandau \& Nafi, 2009, 2010; Montgomery, 1972; O'Ryan, 2006), and the second type maximized the net social benefit, including total abatement costs and environmental damage, or the benefit of the pollution removed (Cabe \& Herriges, 1990; Henderson, 1977; Howe \& Lee, 1983; Kolstad, 1987; Krysiak \& Schweitzer, 2010; Mendelsohn, 1986; Tietenberg, 1974; Wu \& Babcock, 2001).

In the first type of program, the heterogeneity of emission impact is revealed by the heterogeneity of the transfer coefficients (the part of the emissions that reaches the receptor). In the second type of program, the heterogeneity of the impact is revealed by the heterogeneity of marginal contributions to damage, namely the product of transfer coefficients and the vulnerability of receptor sites (variation of the damage, or benefit, for a unit variation of pollution at the receptor site).

Tietenberg $(1995,2006)$ took stock of empirical studies that estimated the reduction of the total abatement cost between uniform and perfectly discriminated policies for the same quality standards. Given the disparities in the results, they deduced that the size of the savings is linked to the context. For example, Atkinson and Lewis (1974) compared the costs of reducing air pollution (particles) in Saint Louis (MO, USA) for uniform and for perfectly discriminated policies, with different quality standards. For standards of 40 to $60 \mu \mathrm{g} / \mathrm{m}^{3}$, the uniform 
policy was at least twice as costly. Nevertheless, Tietenberg (2006) reported that costs seem to converge when the standard is more demanding, but provided no explanation.

Integrating regulation costs can reduce the advantage of perfectly discriminated policies, making it more costly to implement. A "partially" discriminated policy may seem to be a good compromise, with polluters grouped together in permit exchange zones or tax zones.

Mendelsohn (1986), for example, calculated the abatement cost for several possible numbers of zones, within the framework of air pollution by sulfur dioxides in the state of Connecticut. However, these breakdowns are arbitrary and he even admitted that other breakdowns of polluters would undoubtedly be more appropriate.

Destandau and Point (2000) developed a methodology that makes it possible to obtain endogenous effort zones. A simulation of a river shows that gains in efficiency rapidly decrease when the number of zones is increased. In reality, a partial discrimination with few effort zones seems to be sufficient. This can be explained by the fact that the initial breakdown from one to two zones takes place where the savings potential is the highest; the following breakdowns are done in decreasing order of "potential savings". These potential savings depend on the functions of costs and marginal contributions to damage (when the objective is to maximize the net social benefit), or transfer coefficients (when the objective is to reach a quality standard at the lowest possible cost).

Few articles have focused on the factors that have an impact on the advantage of discriminating. Two categories can be distinguished: those that compare uniform control (identical marginal abatement costs or effort) and perfectly discriminated control, and those that study the factors that have an impact on the optimal number of partially discriminated zones.

Concerning the comparison of perfect discrimination and uniform control, the heterogeneity of transfer coefficients is a factor that logically increases the advantage of discriminating (Destandau \& Nafi, 2009; O'Ryan, 2006) since the equalization of marginal pollution costs is optimal with identical transfer coefficients.

Moreover, Tietenberg's (2006) intuition that costs seem to converge when the standard is more demanding was confirmed by O'Ryan (2006) who demonstrated that the advantage of discriminating increases when the standard is not very demanding. More specifically, Destandau and Nafi (2009) found that the discrimination advantage increased for moderately demanding standards. On the one hand, for a relatively undemanding standard, the low level of costs leads to small absolute efficiency gains. On the other hand, when the marginal cost functions are convex and the standard is very limiting, abatement is at a level where the marginal costs are very steep, reducing the gap between the total costs with discriminated and uniform efforts. With linear and unlimited marginal cost functions, the level of the standard has no influence on the discrimination advantage.

The impact of the shape of the cost functions was studied by Kolstad (1987). He used a simple model with two polluters with linear marginal contributions to damage and linear marginal cost functions. He concluded that the discrimination advantage increases when the slope of the marginal costs of one of the two polluters increases (the functions of the other polluter remaining the same).

O'Ryan (2006), and Destandau and Nafi (2009) combined cost function (efficiency) and transfer coefficients (harmfulness). For O'Ryan (2006), there are several polluters divided into two categories, each one with its own linear cost function and its own transfer coefficient. More specifically, some polluters-type 1-are inefficient (steep cost curve) and harmful (high transfer coefficient), and the others-type 2-are efficient and not very harmful. According to him, the discrimination advantage increases when the share of type 2 polluters increases, and when the relationship between the slopes of the cost curves is moderately high. Destandau and Nafi (2009) consider that the discrimination advantage increases when the most efficient polluters (lower abatement costs) are also the least harmful (lowest transfer coefficients), the only case considered by O'Ryan (2006).

As for partial discrimination, the factors that influence the degree of spatial discrimination (optimum number of zones) have been especially studied in the particular case of 'hot spot' risk, following the establishment of tradable permits (Krysiak \& Schweitzer, 2010). The damage depends on the location of buyers and sellers. The spatial segmentation of the market therefore makes it possible to avoid the "hot spots", whereas, on the other hand, it limits potential gains linked to exchanges. The aim of these works was to study this trade-off by determining the optimal number of zones.

For Williams III (2008), polluters have identical cost functions, meaning that the grouping into zones only depends on the polluters' marginal contribution to damage. He found that the number of optimal zones decreases with the marginal cost slope. This result may seem to contradict the results of Kolstad since an increasing optimal number of zones can be linked to an increasing discrimination advantage.

The impact of the benefit slope (or environmental damage) on the advantage of discriminating the abatement 
effort was studied in three articles.

Kolstad (1987) found that the discrimination advantage increased when the ratio of marginal contributions to damage increased. He did not, however, distinguish the impact of the transfer coefficients that, as a result, increases the discrimination advantage and the impact of the vulnerability or the slope of the damage function.

For Williams III (2008), the optimal number of zones increases with the slope of the marginal contribution to damage. In keeping with Kolstad, he does not distinguish the transfer coefficient or the vulnerability.

Finally, Krysiak and Schweitzer (2010) were inspired by the model of Williams III, but added an uncertainty as to the spatial location of two types of polluters: "dirty" or "clean". Since both of these categories of polluters have parallel linear marginal abatement costs, only the original ordinate changes. Without knowledge of the location of pollution emitters, the breakdown into exchange zones is done exogenously, in contrast with Williams III, based on a homogeneous breakdown of the space. Krysiak and Schweitzer (2010) concluded that the breakdown of space is more interesting when the ratio between the slope of the marginal cost and the marginal damage is small.

The aim of this article is to understand how the slope of the environmental benefit function, generated by a reduction of the pollution emitted, affects the advantage of discriminating the abatement effort.

Compare to the existing literature, the innovation of this study is triple: (1) first, the impact of the slope of the environmental benefit function is studied independently of the transfer coefficients, contrary to Kolstad (1987) and Williams III (2008); (2) second, the originality of this paper is to simultaneously study the discrimination by comparing perfect discrimination and uniform control, and by calculating the optimal number of zones in partial discrimination; and (3) third, in partial discrimination, in contrast to Krysiak and Schweitzer (2010), the combination \{zone, effort per zone\} will be determined endogenously using the methodology of Destandau and Point (2000).

After having laid out the hypotheses of the model in Section 2, Section 3 is devoted to a comparison between uniform control and perfectly discriminated control. Finally, in Section 3, we address the role of the slope of the benefit function on the optimal number of partially discriminated zones.

\section{Model Hypotheses}

\subsection{Static Model and Perfect Information}

Like most articles that address spatial issues, we used a static model with perfect information.

Henderson (1977), Fleming and Adams (1997) and Howe and Lee (1983) used a dynamic model, varying the damage function to adapt to the movements of the victims, integrating a cumulative pollution effect, and varying transfer coefficients over time, respectively. The integration of time, however, would not provide an added value to the study of the impact of the benefit function slope on the advantage of discriminating. Likewise, Goetz and Zilberman (2000) described a relatively complex spatio-temporal model, but used a superficial approach to address the spatial issue.

Helfand and House (1995), Wu and Babcock (2001) and Cabe and Herriges (1990) assumed an uncertainty in relation to the transfer coefficients. Since the advantage itself of discrimination is based on the heterogeneity of the transfer coefficients, it is clear that discrimination would have no meaning in a model in which the transfer coefficients are unknown, and that its advantage would decrease with the degree of uncertainty of the coefficients. Once this factor was identified, we assumed that it was known, allowing us to more effectively study the role of the other factors.

\subsection{The Model}

We assumed a continuum of polluters: $x \in[0, X]$, classified in the order of harmfulness (increasing transfer coefficient), so that: $\theta(x)=\theta x$, where $\theta$ is a positive constant.

The polluters have the same cost function: $C(x)=\alpha_{1} a(x)^{\alpha_{2}}$, where $a(x)$ is the pollution abatement per $x$. $\alpha_{1}$ and $\alpha_{2}$ are positive parameters that illustrate the efficiency of polluters (efficiency increases when the value of the parameter $\alpha_{1}$ decreases) and the convexity of the function, respectively. $\alpha_{2}$ is a whole number greater than or equal to 2 .

$\alpha_{1} \alpha_{2} a(x)^{\alpha_{2}-1}$ is the marginal abatement cost, which we refer to as the abatement effort. In fact, a uniform 
policy will lead to an equalization of the marginal abatement costs.

The environmental benefit, $B(Q)$, resulting from an improvement of the ambient quality (reduction $\mathrm{Q}$ of the pollution concentration), can be written as follows:

$$
B(Q)=\beta Q=\beta \int_{0}^{x} \theta(x) a(x) d x
$$

We thus assumed that the benefit was linearly dependent on the pollution removed. This marginal benefit, $\beta$, can be assimilated to the vulnerability of the receiving environment.

The optimization program consists of maximizing the net social benefit: $\Pi$, the difference between the environmental benefit, B, and the sum of the abatement costs, $\mathrm{C}$.

\section{Advantage Linked to Perfect Discrimination According to the Slope of the Environmental Benefit} Function

\subsection{Uniform Abatement Effort and Perfect Discrimination}

Perfect discrimination of the abatement effort makes it possible to obtain a net social benefit, $\Pi_{P D}=B_{P D}-C_{P D}$, greater than the one obtained with a uniformization of the effort, $\Pi_{U}=B_{U}-C_{U}$.

Under perfect discrimination, we look for abatements, a(x), that maximize $\Pi_{P D}$, resulting in the following equations:

$$
\begin{gathered}
\frac{\partial \Pi_{P D}}{\partial a(x)}=\frac{\partial\left(\beta \int_{0}^{X} \theta(x) \cdot a(x) d x-\int_{0}^{X} \alpha_{1} a(x)^{\alpha} 2 d x\right)}{\partial a(x)}=\beta \theta \cdot x-\alpha_{1} \alpha_{2} a(x)^{\alpha_{2}-1}=0 \\
\frac{\partial^{2} \Pi_{P D}}{\partial a(x)^{2}}=-\left(\alpha_{2}-1\right) \alpha_{1} \alpha_{2} a(x)^{\alpha_{2}-2}<0
\end{gathered}
$$

Under perfect discrimination, the abatement is:

$$
a(x)=\left(\frac{\beta \theta \cdot x}{\alpha_{1} \alpha_{2}}\right)^{\frac{1}{\alpha_{2}-1}}, \quad \forall x \in[0, X]
$$

Under uniform control, it is necessary to find the unique abatement, $a_{U}$, that maximizes $\Pi_{U}$, which can be written as:

$$
\begin{gathered}
\frac{\partial \Pi_{P D}}{\partial a_{U}}=\frac{\partial\left(\beta \int_{0}^{X} \theta(x) \cdot a_{U} d x-\int_{0}^{X} \alpha_{1} a_{U}^{\alpha_{2}} d x\right)}{\partial a(x)}=\beta \theta \frac{X^{2}}{2}-\alpha_{1} \alpha_{2} a_{U}^{\alpha_{2}-1} X=0 \\
\frac{\partial^{2} \Pi_{P D}}{\partial a(x)^{2}}=-\left(\alpha_{2}-1\right) \alpha_{1} \alpha_{2} a_{U}^{\alpha_{2}-2} X<0
\end{gathered}
$$

Under uniform control, the abatement is:

$$
a_{U}=\left(\frac{\beta \theta X}{2 \alpha_{1} \alpha_{2}}\right)^{\frac{1}{\alpha_{2}-1}}
$$

\subsection{Maximum Efficiency Gains (Meg)}

In models where the aim was to reach a standard at the lowest cost, Destandau and Nafi (2010) and O'Ryan (2006) built an indicator to measure the advantage of perfect discrimination on uniform regulation. The O'Ryan ratio "R2" consists in dividing the total cost under uniform regulation by the total cost under perfect discrimination. The Destandau and Nafi indicator "Maximum Efficiency Gains", is equal to one minus the 
division of the total cost under perfect discrimination by the total cost under uniform regulation.

In this study, we measure the relative advantage of perfect discrimination by means of the indicator, MEG, described below:

$$
M E G=\frac{\Pi_{P D}-\Pi_{U}}{\Pi_{U}}
$$

With results (1) and (2), the net social benefits can be written as follows:

$$
\begin{gathered}
\Pi_{P D}=\beta \int_{0}^{X} \theta x a(x) d x-\int_{0}^{X} \alpha_{1} a(x)^{\alpha_{2}} d x=\frac{\left(\alpha_{2}-1\right)^{2}(\beta \theta X)^{\frac{\alpha_{2}}{\alpha_{2}-1}} X}{\left(2 \alpha_{2}-1\right) \alpha_{2}\left(\alpha_{2} \alpha_{1}\right)^{\frac{1}{\alpha_{2}-1}}} \\
\Pi_{U}=\beta \int_{0}^{X} \theta x a_{U} d x-\int_{0}^{X} \alpha_{1} a_{U}^{\alpha_{2}} d x=\frac{\left(\alpha_{2}-1\right)(\beta \theta X)^{\frac{\alpha_{2}}{\alpha_{2}-1}} X}{2 \alpha_{2}\left(2 \alpha_{2} \alpha_{1}\right)^{\frac{1}{\alpha_{2}-1}}}
\end{gathered}
$$

Therefore:

$$
M E G=\frac{2^{\frac{\alpha_{2}}{\alpha_{2}-1}}\left(\alpha_{2}-1\right)-2 \alpha_{2}+1}{2 \alpha_{2}-1}
$$

The relative gain of perfect discrimination is independent of the slope of the environmental benefit function. The impact of marginal contribution to damage reported by some authors is therefore due to the heterogeneity of the transfer coefficients. The impact of the heterogeneity of the transfer coefficients cannot be observed here because of the assumption of linearity of these coefficients, but has already been demonstrated by Destandau and Nafi (2010).

The only factor of influence here is the degree of convexity of the cost functions. The greater the convexity is, the more the discrimination appears to serve no purpose. For linear marginal costs $\left(\alpha_{2}=2\right)$, the value of $M E G$ is $1 / 3$. This indicator is less than $5 \%$ for a value of $\alpha_{2}$ greater than 6 (Figure 1).

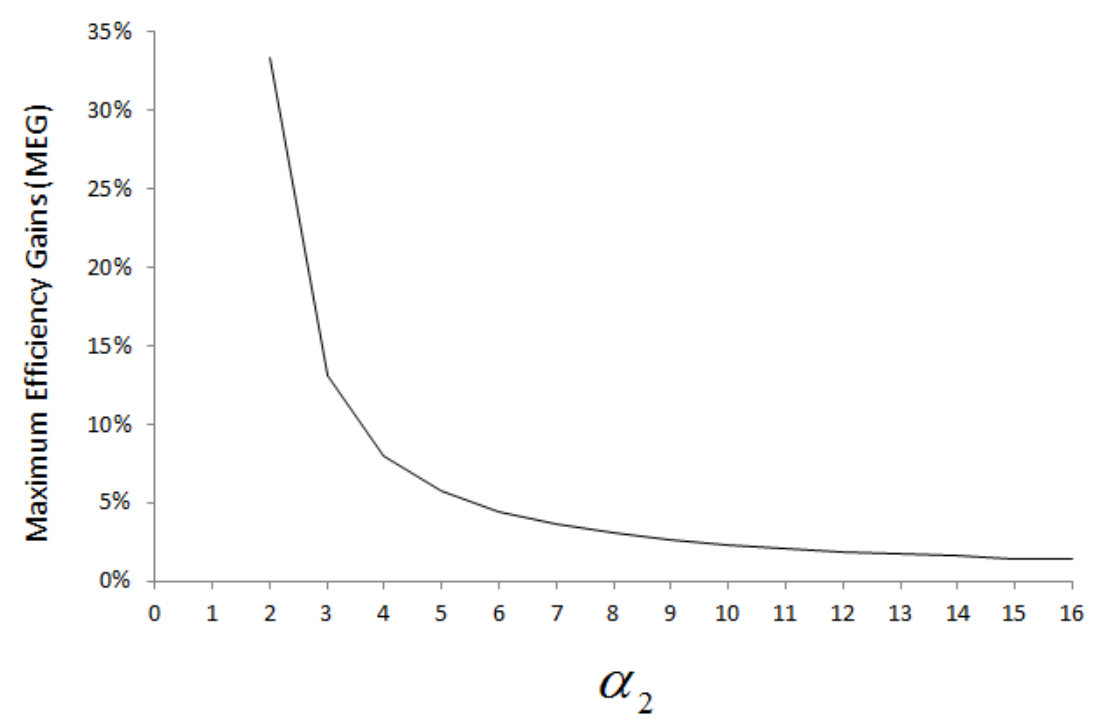

Figure 1. Decrease of the MEG value as a function of the convexity of the cost functions 


\section{Optimal Number of Zones According to the Slope of the Environmental Benefit Curve}

In this section, we have simplified the cost function with $\alpha_{2}=2$, so that the marginal costs are linear, as in Krysiak and Schweitzer (2010).

As explained in the introduction, Mendelsohn (1986) calculated the abatement cost for several possible numbers of zones. However, these breakdowns are arbitrary. He only took the marginal contributions to damage of each pollution source into account, calculating the average for the zone and breaking down the zone into two parts according to whether the contribution was below or above the average. Finally, the most effective breakdown is the one that separates highly populated zones (since its damage function only depends on that) and rural zones. Destandau and Point (2000), on the other hand, developed a methodology that makes it possible to obtain endogenous effort zones. Their methodology consists of four "problems": (1) the "representation problem", making it possible to allocate a social benefit to all types of combinations \{zone, effort per zone\}; (2) the "allocation problem", to determine zones; (3) the "community problem", to assign an effort to each zone; and, finally (4) the "complexity problem" whose aim is to determine the number of zones.

In this section, we used the methodology of Destandau and Point (2000) to determine partial discrimination.

\subsection{Dividing Up the Space}

Dividing up the space into endogenous zones depends on the cost functions and the transfer coefficients of the polluters. With the hypotheses described in Section 1, according to which the cost functions are identical and the transfer coefficients increase linearly, the optimal breakdown of $[0, X]$ into $N$ effort zones ('allocation problem') is done by homogeneous division according to size:

$$
[0, X / N],[X / N, 2 X / N], \ldots,[(n-1) X / N, n X / N], \ldots,[(N-1) X / N, X] .
$$

The effort will be uniform in each effort zone:

$$
a(x)=a_{n}, \forall x \in n, \forall n \in[1, N]
$$

Krysiak and Schweitzer also divided up the space into homogeneous zones, but exogenously. They allocated the same quantity of permits to each zone, whereas we determined (see Section 4.3 below) the pollution that should be removed from each zone endogenously, what Destandau and Point (2000) refer to as the "community problem".

\subsection{Net Social Benefit as A Function of $a_{n}$}

We integrated a unit cost for zone $z$ that was proportional to the number of zones.

The net social benefit is:

$$
\Pi_{N}=B(Q)-\int_{0}^{X} C(x) d x-z N
$$

Then:

$$
\begin{aligned}
& \Pi_{N}=\beta \sum_{n=1}^{N} \int_{\frac{(n-1) X}{N}}^{\frac{n X}{N}} \theta x a_{n} d x-\sum_{n=1}^{N} \int_{\frac{(n-1) X}{N}}^{\frac{n X}{N}} \alpha_{1} a_{n}^{2} d x-z N \\
\Leftrightarrow & \Pi_{N}=\frac{\beta \theta X^{2}}{2 N^{2}} \sum_{n=1}^{N} a_{n}(2 n-1)-\frac{\alpha_{1} X}{N} \sum_{n=1}^{N} a_{n}^{2}-z N
\end{aligned}
$$

The net social benefit makes it possible to characterize each combination zzone, effort per zone\}. This is considered to be a "representation problem".

\subsection{Effort $a_{n}$ for Each Zone}

On the basis of Equation (4), we can deduce the abatement cost (marginal abatement cost) that will be required in each of the zones ("community problem"), by deriving the net social benefit per $a_{n}$. 


$$
\begin{gathered}
\frac{\partial \Pi_{N}}{\partial a_{n}}=\frac{\beta \theta X^{2}(2 n-1)}{2 N^{2}}-\frac{2 \alpha_{1} X}{N} a_{n}=0 \\
\frac{\partial^{2} \Pi_{N}}{\partial a_{n}^{2}}=-\frac{2 \alpha_{1} X}{N}<0
\end{gathered}
$$

Therefore:

$$
a_{n}=\frac{\beta \theta X(2 n-1)}{4 \alpha_{1} N}, \forall n \in[1, N]
$$

\subsection{Net Social Benefit as a Function of N}

On the basis of Equations (4) and (5), the net social benefit becomes:

$$
\begin{gathered}
\Pi_{N}=\frac{\beta \theta X^{2}}{2 N^{2}} \sum_{n=1}^{N} \frac{\beta \theta X}{4 \alpha_{1} N}(2 n-1)^{2}-\frac{\alpha_{1} X}{N} \sum_{n=1}^{N} \frac{\beta^{2} \theta^{2} X^{2}(2 n-1)^{2}}{16 \alpha_{1}^{2} N^{2}}-z N \\
=\frac{\beta^{2} \theta^{2} X^{3}}{16 \alpha_{1} N^{3}} \sum_{n=1}^{N}(2 n-1)^{2}-z N=\frac{\beta^{2} \theta^{2} X^{3}}{16 \alpha_{1} N^{3}}\left[4 N^{3}-N\right]-z N \\
\Leftrightarrow \Pi_{N}=\frac{\beta^{2} \theta^{2} X^{3}}{16 \alpha_{1}}\left[\frac{4 N^{2}-1}{N^{2}}\right]-z N
\end{gathered}
$$

\subsection{Optimal Number of Zones}

The optimal number of zones ('complexity problem') can be deduced from the derivative of the net social benefit (6) in relation to $\mathrm{N}$ :

$$
\begin{aligned}
& \frac{\partial \Pi_{N}}{\partial N}=\frac{\beta^{2} \theta^{2} X^{3}}{8 \alpha_{1} N^{3}}-z=0 \\
& \frac{\partial^{2} \Pi_{N}}{\partial N^{2}}=-\frac{3 \beta^{2} \theta^{2} X^{3}}{8 \alpha_{1} N^{4}}<0
\end{aligned}
$$

The optimal number of zones is:

$$
N=\left(\frac{\beta^{2} \theta^{2} X^{3}}{8 \alpha_{1} z}\right)^{1 / 3}
$$

The optimal number of zones increases with the slope of the benefit function, with the transfer coefficients and with the number of polluters. It decreases with the unit cost of discrimination and the slope of the marginal costs.

This result casts a new light on the results obtained in Section 5. The slope of the environmental benefit function has an impact on discrimination, not in terms of the perfect discrimination advantage in relation to uniform control, but by increasing the optimal number of partially discriminated zones.

\section{Discussion and Conclusion}

Since the beginning of the 1970s, many articles have dealt with the advantages of discriminating the abatement effort when pollution has a heterogeneous impact according to the location of the emitter. However, it is only recently that some authors have attempted to identify the impact of certain model parameters on the advantage of 
this type of discrimination. We know that the advantage of discriminating the abatement effort increases when the transfer coefficients are the most heterogeneous, when the most efficient polluters are the least harmful ones, and when the quality standard to be reached is not too demanding.

The aim of this article was to fill in the gaps concerning the impact of the slope of the environmental benefit function that had not been adequately studied in the past.

In this paper, the impact of the slope of the environmental benefit function is studied independently of the transfer coefficients; at the same time, in comparing perfect discrimination and uniform control, and in calculating the optimal number of zones in partial discrimination. In partial discrimination the number of zones was determined endogenously using the methodology of Destandau and Point (2000).

The results show that the slope of this function does not have an impact on the relative gain when we change from uniform control to perfectly discriminated control. This result was obtained by isolating this parameter of the transfer coefficients, in contrast with some authors who hold that the marginal contribution to damage (product of the transfer coefficients and the benefit function) has an impact on the discrimination advantage. We now know that this result was only due to the role of the transfer coefficients.

It therefore appears here that the degree of vulnerability of the receptor site has no influence on the advantage of perfectly discriminating the abatement effort of the emitters. However, in the models whose objective was to reach a standard at a minimal cost, it appears that a greater demand on these standards made discrimination less interesting. The difference is due to the fact that in a model whose objective is to maximize the net social benefit, the environmental quality obtained is not the same under uniform and discriminated control. Therefore, the two methods may seem to be comparable in terms of costs, but discrimination may generate a greater benefit by improving the quality.

Our second result, however, casts a new light on the preceding one because by considering a partial discrimination of the abatement effort, the number of zones must be greater if the slope of the benefit function increases. This parameter therefore increases the discrimination advantage.

The majority of the policies concerning water pollution fix standards to be reached at the lowest cost. However, the European Water Framework Directive (European Commission, 2000) should be mentioned here since a cost-benefit analysis can allow the member states to adjust the standard to their local characteristics. In this case, our results show that the advantage of discriminating does not depend on the local sensibility. Nevertheless, in partial discrimination, the higher the local sensibility is, the greater the number of regulation zones must be (for example, zones where an effluent tax rate will be different).

It could be interesting in the future to explore which complementary results could be obtained with other shapes of cost or benefit functions.

\section{References}

Atkinson, S. E., \& Lewis, D. H. (1974). A Cost-Effectiveness Analysis of Alternative Air Quality Control Strategies. Journal of Environmental Economics and Management, 1, 237-250. http://dx.doi.org/10.1016/0095-0696(74)90005-9

Cabe, R., \& Herriges, J. H. (1990). The Regulation of Heterogeneous Non-Point Sources of Pollution Under Imperfect Information (Unpublished results). Center for Agricultural and Rural Development. Iowa State University.

Destandau, F., \& Nafi, A. (2009). Programmes de mesures de la Directive Cadre sur l'eau : doit-on discriminer l'effort de dépollution? Revue d'Economie Politique, 119(1), 96-118.

Destandau, F., \& Nafi, A. (2010). What is the best distribution for pollution abatement efforts? Information for optimizing the WFD Programs of measures. Environmental and Resource Economics, 46(3), 337-358. http://dx.doi.org/10.1007/s10640-010-9344-y

Destandau, F., \& Point, P. (2000). Cheminement d'impact et partition efficace de l'espace. Revue Economique 5l(3), 609-620. http://dx.doi.org/10.2307/3503149

European Commission. (2000). Directive 2000/60/EC of the European Parliament and of the Council establishing a framework for Community action in the field of water policy. OJL327, 22.12.2000.

Fleming, R. A., \& Adams, R. M. (1997). The Importance of Site-Specific Information in the Design of Policies to Control Pollution. Journal of Environmental Economics and Management, 33, 347-358. http://dx.doi.org/10.1006/jeem.1997.0990 
Goetz, R. U., \& Zilberman, D. (2000). The dynamics of spatial pollution: The case of phosphorus runoff from agricultural land. Journal of Economic Dynamics \& Control, 24, 143-163. http://dx.doi.org/10.1016/S0165-1889(98)00067-0

Helfand, G. E., \& House, B. (1995). Regulating Nonpoint Source Pollution under Heterogeneous Conditions. American Journal of Agricultural Economics, 77(4), 1024-1032. http://dx.doi.org/10.2307/1243825

Henderson, J. V. (1977). Externalities in a spatial context. Journal of Public Economics, 7, 89-110. http://dx.doi.org/10.1016/0047-2727(77)90038-X

Howe, C. W., \& Lee, D. R. (1983). Priority Pollution Rights: Adapting Pollution Control to a Variable Environment. Land Economics, 59(2), 141-149. http://dx.doi.org/10.2307/3146044

Kolstad, C. D. (1987). Uniformity versus Differentiation in Regulating Externalities. Journal of Environmental Economics and Management, 14, 386-399. http://dx.doi.org/10.1016/0095-0696(87)90029-5

Krysiak, F. C., \& Schweitzer, P. (2010). The optimal size of a permit market. Journal of Environmental Economics and Management, 60, 133-143. http://dx.doi.org/10.1016/j.jeem.2010.05.001

Mendelsohn, R. (1986). Regulating Heterogeneous Emissions. Journal of Environmental Economics and Management, 13, 301-312. http://dx.doi.org/10.1016/0095-0696(86)90001-X

Montgomery, W. D. (1972). Markets in Licences and Efficient Pollution Control Programs. Journal of Economic Theory, 5(3), 395-418. http://dx.doi.org/10.1016/0022-0531(72)90049-X

O'Ryan, R. E. (2006). Factors that determine the cost-effectiveness ranking of second-best instruments for environmental regulation. Journal of Regulatory Economics, 30(2), 179-198. http://dx.doi.org/10.1007/s11149-006-0014-5

Tietenberg, T. H. (1974). Derived Decision Rules for Pollution Control in a General Equilibrium Space Economy. Journal of Environmental Economics and Management, 1, 3-16. http://dx.doi.org/10.1016/0095-0696(74)90014-X

Tietenberg, T. H. (1995). Tradeable Permits for Pollution Control when Emission Location Matters: What have we learned? Environmental and Resource Economics, 5, 95-113. http://dx.doi.org/10.1007/BF00693018

Tietenberg, T. H. (2006). Emissions Trading: Principles and Practice (2nd ed.). Resources for the Future, Washington DC, USA.

Williams III, R. C. (2008). Cost-Effectiveness vs. Hot spots: Determining the Optimal size of Emissions Permits Trading Zones (Unpublished results). Department of Economic, University of Texas, Austin.

Wu, J., \& Babcock, B. A. (2001). Spatial Heterogeneity and the Choice of Instruments to Control Nonpoint $\begin{array}{lllll}\text { Pollution. Environmental and Resource Economics, 18, 192. } & \text { 18, }\end{array}$ http://dx.doi.org/10.1023/A:1011164102052

\section{Copyrights}

Copyright for this article is retained by the author(s), with first publication rights granted to the journal.

This is an open-access article distributed under the terms and conditions of the Creative Commons Attribution license (http://creativecommons.org/licenses/by/3.0/). 